\title{
BMJ Open Twelve-year persistence of inequalities in antenatal care utilisation among women in Tanzania: a decomposition analysis of population-based cross- sectional surveys
}

Deogratius Bintabara (D) , ${ }^{1}$ Namanya Basinda ${ }^{2}$

To cite: Bintabara D, Basinda N. Twelve-year persistence of inequalities in antenatal care utilisation among women in Tanzania: a decomposition analysis of population-based crosssectional surveys. BMJ Open 2021;11:e040450. doi:10.1136/ bmjopen-2020-040450

- Prepublication history and supplemental material for this paper are available online. To view these files, please visit the journal online (http://dx.doi. org/10.1136/bmjopen-2020040450).

Received 13 May 2020 Revised 05 January 2021 Accepted 13 January 2021

Check for updates

(c) Author(s) (or their employer(s)) 2021. Re-use permitted under CC BY-NC. No commercial re-use. See rights and permissions. Published by BMJ.

${ }^{1}$ Department of Community Medicine, The University of Dodoma, Dodoma, Tanzania ${ }^{2}$ Department of Public Health, Catholic University of Health and Allied Sciences, Mwanza, Tanzania

Correspondence to Dr Deogratius Bintabara; bintabaradeo@gmail.com

\section{ABSTRACT}

Objective This study was undertaken to assess the trend and contributors of socioeconomic inequalities in antenatal care (ANC) utilisation among women of reproductive age in Tanzania from 2004 to 2016.

Design Population-based cross-sectional surveys. Setting This study analysed nationally representative data for women of reproductive age obtained from the 2004-2016 Tanzania Demographic Health Surveys.

Primary outcome measure The outcome variables analysed in this study are: (1) attendance of ANC and (2) accessing adequate antenatal care.

Analytical methods The concentration curve and the concentration index were used to measure socioeconomic inequality in attending and accessing adequate ANC. The concentration index was decomposed to identify the factors explaining the observed socioeconomic inequality of these two outcomes.

Results The concentration index for attending at least four ANC visits increased from 0.169 in 2004 to 0.243 in $2016(p<0.01)$. Similarly, for accessing adequate care, the index increased from 0.147 in 2004 to 0.355 in $2016(p<0.01)$. This indicates the significant increase in socioeconomic inequalities (favouring wealthier women) for these two outcomes over time. Furthermore, the results show that wealth status was the largest contributor to inequality in both attending at least four visits $(71 \%, 50 \%$ and $70 \%)$ and accessing adequate ANC $(50 \%, 42 \%$ and $51 \%$ ) in 2004, 2010 and 2016, respectively, in favour of wealthier women $(p<0.05)$. The other contributors to socioeconomic inequalities in ANC utilisation were maternal education and type of residence.

Conclusion Over the 12 years of surveys, there was no reduction in socioeconomic inequalities in ANC utilisation in Tanzania. Therefore, the efforts of achieving universal health coverage should focus on reducing wealth-related inequality and improving women's education from poor households.

\section{INTRODUCTION}

Although the Sustainable Development Goals (SDGs) emphasise that no one should be left behind, the majority of women in developing countries especially in sub-Saharan
Strengths and limitations of this study

- This is the first study to using two important outcomes: (1) attending at least four visits and (2) accessing adequate care to assess the trend of socioeconomic inequalities in antenatal care utilisation in Tanzania.

- Also, the use of nationally representative samples with high response rates provides greater statistical power and generalisability to settings with a similar context.

- The use of cross-sectional surveys meant that causality assumptions could not be inferred. Consequently, the results should be interpreted with caution.

- Recall bias may have been introduced as a result of including women who had live births in the 5 years preceding the surveys. This might lead to either an overestimation or underestimation of the association between outcomes and independent variables.

Africa (SSA) are still experiencing difficulties in the utilisation of maternal health services. ${ }^{12}$ Moreover, there are increasing concerns regarding inequalities in the utilisation of maternal health services in that region. ${ }^{3} 4$ Antenatal care (ANC) is among the important aspects to evaluate the utilisation of maternal healthcare. It is one of the six pillars of the Safe Motherhood Initiative, which provides screening and preventive interventions that are crucial for better pregnancy outcomes. ${ }^{45}$ Therefore, in early 2000 , the WHO promoted a focused ANC model recommending pregnant women to attend a minimum of four visits. ${ }^{6}$ Later in 2016, WHO released an updated version of the ANC model recommending a minimum of eight visits, ${ }^{7}$ though, the majority of SSA countries still implement the previous model of ANC.

Based on previous studies, the assessment of ANC utilisation was measured by using two 
major indicators: (1) attending at least four ANC visits (ANC4+) and (2) accessing adequate ANC (aANC). ${ }^{89}$ These two indicators are considered as appropriate use of ANC as they tend to significantly improve early identification of risk factors during pregnancy with prompt treatment or prevention. ${ }^{10}$ Poor utilisation of these two ANC indicators could substantially increase the risk of severe adverse pregnancy outcomes. ${ }^{11}$ Previous studies that evaluated the ANC utilisation by using these indicators reported that most pregnant women in SSA did not attend ANC4+ and/or access aANC. ${ }^{12}$ In Tanzania, only half of the pregnant women attended ANC4+. ${ }^{13}$ This low attendance in Tanzania and other SSA countries have been strongly associated with socioeconomic factors. 81415

The socioeconomic factors such as maternal age, education, residence, wealth and occupation were much discussed as the major influence of ANC utilisation that disproportionally favours wealthier women. ${ }^{16-18}$ Although little is known about the contributions of these factors to the inequalities in ANC utilisation in Tanzania, they have been well assessed and discussed in other developing countries such as in South Asian countries. ${ }^{19-21}$ Previous studies in the later region highlight wealthrelated inequalities as the major driver of ANC utilisation in favour of wealthier women. ${ }^{22}{ }^{23}$ Besides, some studies deepen their research questions to explore the impact of the region and geographical differences on the association of wealth-related inequalities and ANC utilisation. $^{24}{ }^{25}$ These kinds of literature provide the current status of inequalities in developing countries and stand as a starting point to explore whether a similar situation exists in other regions of developing countries such as Tanzania.

Despite the limited information about the inequalities in ANC utilisation in Tanzania, the government has been increasing the number of public primary health facilities that provide free maternal health services since 1994. Furthermore, the provision of free maternal services has been much insisted and indicated as a priority component of national health policy since $2006 .{ }^{26}{ }^{27}$ This resulted in an increase in the coverage of ANC by skilled providers (96\%-98\%) between 2010 and 2016. ${ }^{13}$ Even with these strong health policies and increased coverage of ANC services in Tanzania, there is uncertainty about whether they have substantially reduced or eliminated the gaps of socioeconomic inequalities in ANC utilisation. Moreover, limited studies at the local and national levels regarding socioeconomic inequalities in ANC utilisation prompted this research. Therefore, this paper aimed to assess the trend and potential contributors to socioeconomic inequalities in ANC utilisation among pregnant women in Tanzania from 2004 to 2016.

This study contributes to the current literature on ANC utilisation in Tanzania in the following ways. It provides the current magnitude and trends over time in ANC utilisation by using two important indicators (ANC4+ andaANC). Besides, the findings of the present study will help to improve the strategies aimed to eliminate inequalities in ANC utilisation in Tanzania and other countries with a similar setting.

\section{METHODS}

\section{Data source}

The current study used data from the three most recent rounds (2004, 2010 and 2016) of Tanzania Demographic Health Surveys (TDHS). All were nationally representative household surveys undertaken by Tanzania's National Bureau of Statistics in collaboration with the Office of the Chief Government Statistician, Zanzibar; the Ministry of Health, Community Development, Gender, Elderly and Children, Tanzania Mainland; and the Ministry of Health, Zanzibar. Financial and technical support for the surveys was provided by Inner City Fund (ICF) International under the Demographic Health Survey (DHS) programme. The TDHSs have been conducted every 4 years.

\section{Sampling technique}

For 2004, 2010 and 2016, TDHS employed two-stage cluster sampling methods. At the first stage, the primary sampling units (clusters) were selected. ${ }^{28}$ In the second stage, a total of 22 households were systematically selected from each cluster, yielding a representative probability sample of 10 312, 10300 and 13376 households for 2004, 2010 and 2016 TDHSs. However, 9735 (99\% response rate), 9623 (99\% response rate) and 12563 (98\% response rate) of existing households in 2004, 2010 and 2016, respectively, were successfully interviewed. The details about sampling and other methodology information can be found elsewhere. ${ }^{13}$

\section{Study sample and subjects}

In the interviewed households, the total numbers of interviewed women were as follows: 10139 women in 2004; 10329 women in 2010; and 13266 women in 2016 with an average response rate of $97 \%$. In this study, we included women aged 15-49 years who had a live birth in the 5 years preceding the survey and resulting samples of 5772 women, 5519 women and 7079 women in 2004, 2010 and 2016, respectively. These sample sizes were used to assess the attendance of ANC. During the assessment of whether women received adequate ANC, we removed all women who reported that they had not attended any ANC visit, and therefore, the used sample sizes were 5593 women, 5404 women and 6937 women in 2004, 2010 and 2016 , respectively. The included subjects in this study had all variables of interest; that is, there was no missing data.

\section{Measurement of variables \\ Outcome variables}

The outcome variables analysed in this study are: (1) attending ANC4+, which considered 'Yes' if women attended at least four visits, otherwise considered 'No'; and (2) accessing aANC, which considered 'Yes' if a woman reported receiving all of the following: (1) iron/ 
folate tablets or syrup, (2) antimalarial drugs, (3) blood pressure measured, (4) urine sample taken, (5) blood sample taken and (6) intestinal parasite drugs, otherwise considered 'No'. These two outcome variables have been chosen based on evidence from previous studies that indicated that completion of recommended ANC4+ is positively associated with receiving aANC (high-quality ANC services). ${ }^{29} 30$

\section{Independent variables}

The household wealth index in TDHS was used as the primary independent variable, while the control variables were maternal age, residence, education level, marital status and employment status. These variables were selected based on previous studies that assessed the correlates of ANC utilisation in Tanzania. ${ }^{8}{ }^{31}$ Table 1 summarises the measurement of these variables.

\section{Analytical methods}

Descriptive analysis, multivariable logistic regression modelling and assessment of wealth-related inequalities over time have been performed in this study. We run the multivariable logistic regression analysis to assess the relationship between wealth index and ANC utilisation outcomes. We included the interaction terms between the wealth index (as continuous) and the year of the survey and then plotted the predicted probabilities to show the wealth gradient over time as presented in other studies. ${ }^{24}{ }^{32}$ We preferred to use the wealth index as a continuous variable when assessing the wealth-year interactions since an analysis of the interaction between five wealth categories and 3 years of surveys would be statistically underpowered. A similar approach has been used previously. ${ }^{24}$

In this study, three approaches to evaluate socioeconomic inequalities in ANC utilisation outcomes were used: (1) the construction of concentration curves (CCs), (2) the computation of concentration indices (Cs) and (3) the decomposition analysis.

\section{Concentration curves}

The CCs were used to evaluate the patterns of inequalities for each measure of ANC utilisation (ANC4+ andaANC). The CCs plot the cumulative percentage of the outcome variable (y-axis) against the cumulative percentage of the population ranked by household socioeconomic status (using a raw score of wealth index), beginning with the poorest and ending with the richest (x-axis). ${ }^{33}{ }^{34}$ In other words, they plot shares of outcome variable against quintiles of the household wealth index. If everyone, irrespective of her wealth index class, has the same value of ANC utilisation, the $\mathrm{CC}$ will be a $45^{\circ}$ (diagonal) line, starting from the bottom left-hand corner to the top right-hand corner. This diagonal line is known as a line of equality. If, by contrast, the outcome variables (ANC4+ or aANC) take higher (lower) value among poorer women, the $\mathrm{CC}$ will lie above (below) the line of equality. For example, the
Table 1 A summary of the measurement of independent variables

\begin{tabular}{|c|c|c|}
\hline Variable & Values & Measurement \\
\hline \multirow[t]{5}{*}{ Wealth index } & Poorest & $\begin{array}{l}\text { The first lowest quintile of the } \\
\text { sample population distribution. }\end{array}$ \\
\hline & Poorer & $\begin{array}{l}\text { The second lowest quintile of the } \\
\text { sample population distribution. }\end{array}$ \\
\hline & Middle & $\begin{array}{l}\text { The third (middle) quintile of the } \\
\text { sample population distribution. }\end{array}$ \\
\hline & Richer & $\begin{array}{l}\text { The fourth quintile of the sample } \\
\text { population distribution. }\end{array}$ \\
\hline & Richest & $\begin{array}{l}\text { The highest quintile of the sample } \\
\text { population distribution. }\end{array}$ \\
\hline \multirow{7}{*}{$\begin{array}{l}\text { Maternal age } \\
\text { (years) }\end{array}$} & $15-19$ & Age between 15 and 19 years. \\
\hline & $20-24$ & Age between 20 and 24 years. \\
\hline & $25-29$ & Age between 25 and 29 years. \\
\hline & $30-34$ & Age between 30 and 34 years. \\
\hline & $35-39$ & Age between 35 and 39 years. \\
\hline & $40-44$ & Age between 40 and 44 years. \\
\hline & $45-49$ & Age between 45 and 49 years. \\
\hline \multirow[t]{2}{*}{ Residence } & Urban & $\begin{array}{l}\text { For households located in } \\
\text { cities, municipalities and town } \\
\text { councils gazetted under the Local } \\
\text { Government Act, } 1982 .{ }^{52}\end{array}$ \\
\hline & Rural & $\begin{array}{l}\text { For households that were located } \\
\text { outside the urban areas. }\end{array}$ \\
\hline \multirow[t]{4}{*}{$\begin{array}{l}\text { Education } \\
\text { level }\end{array}$} & None & $\begin{array}{l}\text { For women who had not received } \\
\text { any kind of formal education. }\end{array}$ \\
\hline & Primary & $\begin{array}{l}\text { For women who completed } \\
\text { primary education level. }\end{array}$ \\
\hline & Secondary & $\begin{array}{l}\text { For women who completed } \\
\text { secondary education level. }\end{array}$ \\
\hline & Highest & $\begin{array}{l}\text { For women who completed college } \\
\text { and all university level. }\end{array}$ \\
\hline \multirow[t]{2}{*}{ Marital status } & No spouse & $\begin{array}{l}\text { For women who were single, } \\
\text { divorced, separated or widowed. }\end{array}$ \\
\hline & $\begin{array}{l}\text { Living with } \\
\text { a spouse }\end{array}$ & $\begin{array}{l}\text { For women who were married or } \\
\text { living with the partner during the } \\
\text { interview. }\end{array}$ \\
\hline \multirow[t]{2}{*}{ Employment } & Employed & $\begin{array}{l}\text { For women who reported to be } \\
\text { employed and paid in salary in } \\
\text { terms of cash. }\end{array}$ \\
\hline & $\begin{array}{l}\text { Not } \\
\text { employed }\end{array}$ & $\begin{array}{l}\text { For those who did not have any } \\
\text { kind of job and paid in terms of } \\
\text { cash. }\end{array}$ \\
\hline
\end{tabular}

farther the curve is below the line of equality, the more concentrated the ANC utilisation is among the rich.

\section{Concentration indices}

Compared with CCs, the Cs have an additional advantage of quantifying the degree of socioeconomic-related inequality in healthcare variables such as ANC utilisation. This $\mathrm{C}$ is defined as 'twice the area between CC and the line of equality'. It takes the values bounded between -1 
and +1 . If the index takes the value of ' 0 ', it indicates that there is no socioeconomic-related inequality. However, it takes a positive value when the curve lies below the line of equality, indicating the disproportionate concentration of health variable among the rich, and a negative value when it lies below the line of equality. If the health variable is 'good' such as ANC utilisation, an index with a positive value indicating ANC utilisation is more among the rich. ${ }^{33}$ For computation, the $\mathrm{C}$ can be calculated by using the following formula (1).

$$
C=\frac{2}{\mu} \operatorname{cov}(y, r)
$$

Because the outcome variables were binary, the bounds of the $C$ may not lie between -1 and +1 . Wagstaff and Erreygers concentration indices are two techniques to account for the mentioned issues. ${ }^{35} 36$ Therefore, the current study used the Erreygers version of the $\mathrm{C}$ as this index satisfies four properties of the rank-dependent measure of inequality. ${ }^{24} 37$

\section{Decomposition analysis}

Since the decomposition of healthcare inequality bases on the assumption that healthcare is a linear function of the outcome variable, therefore, the decomposition of Cs is computed using the predictions from the linear regression analysis. ${ }^{38}{ }^{39}$ In this study, we decomposed the Cs as previously described by Wangstaff $e t a l^{39}$ to estimate the contribution of each independent variable to the inequalities in ANC utilisation. They demonstrate that the contributions of each factor to income-related health inequality is the product of the sensitivity of heath concerning that factor and the degree of income-related inequality in that factor. ${ }^{39}$ Therefore, the overall $\mathrm{C}$ for the predicted outcome variable is the result of the summation of the contributions made by all independent variables under exploration. This can be shown mathematically by using the following formula (2):

$$
C I=\sum_{k}\left(\beta_{k} \bar{x}_{k} / \mu\right) \complement I_{k}+G C I_{\varepsilon} / \mu
$$

Where $\mathrm{C}$ is the concentration index, $\mathrm{k}$ is variables, $x_{k}$ is the mean of $x_{k}, C_{k}$ is the concentration index for $x_{k}, \mu$ is the mean of the health outcome and $G C$ is the generalised concentration index for the error term. The $\left(\underline{\beta}_{k} \underline{X}_{k}\right) /{ }_{\mu} C_{k}$ component in the formula represents the explained part of the concentration index of the outcome variable, and the GC $\varepsilon / \mu$ represents the residual component.

STATA V.16 (StataCorp, College Station, Texas, USA) was used for analysis in the present study. For all analyses, the Stata survey set commands were used to adjust for the variability of clustering, and all the estimates were weighted to correct for non-responses and disproportionate sampling.

\section{Ethics statement}

This study was based on an analysis of existing public domain survey datasets that are freely available online with all identifier information detached. The original TDHSs were reviewed by the Institution Review Board
(IRB) of ICF Macro at Calverton in the USA and by the National Institute of Medical Research IRB in Tanzania. Both IRBs ensured that the surveys complied with the laws and norms of Tanzania. The participants were adequately informed about all relevant aspects of the survey, including its objective and interview procedures. All study subjects who accepted participating in the study signed informed consent before the interviews.

\section{Patient and public involvement statement}

Patients and the public were not involved in the analysis of this study.

\section{RESULTS}

\section{Summary statistics}

Table 2 summarises ANC4+ andaANC in Tanzania according to women's background characteristics. The proportion of women who attended ANC4+ decreased from $61.5 \%$ in 2004 to $42.8 \%$ in 2010 then to $50.1 \%$ in 2016. However, between 2010 and 2016, there was a significant increase in attending ANC4+ visits among women of the groups below 30 years of age, those in the third, fourth and highest wealth quintiles and those living in urban settings. The proportion of accessing aANC increased from $15.1 \%$ in 2004 to $23.8 \%$ in 2010 and further to $37.4 \%$ in 2016 . Though the proportion of attending ANC4+ decreased over time (mainly among the poorest women), there was a significant increase in accessing aANC in all wealth quintiles (even among the poorest women). This suggests that women from all wealth quintiles have equal access to aANC as the trend of availability of ANC services increases overtime at the facilities.

\section{Relationship between the wealth index and ANC outcomes}

Table 3 shows the adjusted OR (AOR) with 95\% Confidence Interval (CI) from the multivariable logistic regression analysis. The models presented assessed the relationship between wealth index and our two ANC outcome variables by interacting wealth (as continuous) and year of the survey. The models also include controlling variables (maternal age, residence, maternal education, marital status and employment). The models indicate that each unit increase in the wealth index is significantly associated with higher odds of attending ANC4+ (AOR=1.17; 95\% CI 1.08 to $1.28)$ and accessing aANC (AOR $=1.15$; 95\% CI 1.08 to 1.22). Furthermore, compared with 2004, the odds of attending ANC4+ were higher in $2010 \quad(\mathrm{AOR}=1.58$; 95\% CI 1.08 to 2.30$)$ and 2016 (AOR=2.36; 95\% 1.67 to 3.34). However, in a similar comparison, the odds of accessing aANC decreased by $54 \%$ and $50 \%$ in 2010 and 2016, respectively. The interaction terms between wealth and year of the survey were not significant for all ANC outcomes, signifying no evidence of effect modification by year of the survey. Besides, we found our two 
Table 2 Rates of ANC4+ and aANC by women's characteristics in Tanzania in 2004, 2010 and 2016

\begin{tabular}{|c|c|c|c|c|c|c|}
\hline \multirow[b]{2}{*}{ Variable } & \multicolumn{3}{|c|}{ Attending at least four ANC visits } & \multicolumn{3}{|c|}{ Accessing adequate ANC } \\
\hline & $\begin{array}{l}2004 \\
(n=5772)\end{array}$ & $\begin{array}{l}2010 \\
(n=5519)\end{array}$ & $\begin{array}{l}2016 \\
(n=7079)\end{array}$ & $\begin{array}{l}2004 \\
(n=5593)\end{array}$ & $\begin{array}{l}2010 \\
(n=5404)\end{array}$ & $\begin{array}{l}2016 \\
(n=6937\end{array}$ \\
\hline \multicolumn{7}{|l|}{ Maternal age (years) } \\
\hline $15-19$ & 62.01 & 36.12 & 47.35 & 20.35 & 20.66 & 31.45 \\
\hline $20-24$ & 60.39 & 42.91 & 51.51 & 17.04 & 21.98 & 36.81 \\
\hline $25-29$ & 63.51 & 42.00 & 52.09 & 15.45 & 24.42 & 41.22 \\
\hline $30-34$ & 59.98 & 47.80 & 50.88 & 13.31 & 26.87 & 40.06 \\
\hline $35-39$ & 62.22 & 38.95 & 52.26 & 13.13 & 24.34 & 35.97 \\
\hline $40-44$ & 61.94 & 46.35 & 46.46 & 11.64 & 22.41 & 33.05 \\
\hline $45-49$ & 56.46 & 44.46 & 44.40 & 6.15 & 21.09 & 31.12 \\
\hline \multicolumn{7}{|l|}{ Wealth status } \\
\hline Poorest & 52.16 & 37.10 & 39.27 & 9.95 & 15.06 & 21.87 \\
\hline Poorer & 59.00 & 34.85 & 43.17 & 10.73 & 14.33 & 24.93 \\
\hline Middle & 58.94 & 39.89 & 46.57 & 9.96 & 18.22 & 32.12 \\
\hline Richer & 63.39 & 47.11 & 56.06 & 15.07 & 33.05 & 46.01 \\
\hline Richest & 75.59 & 58.72 & 69.86 & 31.30 & 42.02 & 64.02 \\
\hline \multicolumn{7}{|l|}{ Residence } \\
\hline Rural & 58.64 & 39.21 & 45.15 & 11.15 & 18.05 & 28.01 \\
\hline Urban & 71.38 & 54.90 & 63.64 & 28.79 & 42.71 & 59.28 \\
\hline \multicolumn{7}{|l|}{ Maternal education } \\
\hline None & 54.09 & 34.89 & 40.86 & 8.10 & 15.35 & 21.91 \\
\hline Primary & 62.63 & 43.12 & 49.96 & 16.35 & 24.47 & 37.40 \\
\hline Secondary & 80.52 & 64.21 & 64.07 & 30.55 & 43.67 & 54.93 \\
\hline Higher & 85.18 & 91.19 & 85.01 & 30.63 & 42.60 & 65.33 \\
\hline \multicolumn{7}{|l|}{ Marital status } \\
\hline No spouse & 59.31 & 45.43 & 54.38 & 18.35 & 26.33 & 42.27 \\
\hline Living with a spouse & 61.84 & 42.27 & 49.79 & 14.50 & 23.25 & 36.24 \\
\hline \multicolumn{7}{|l|}{ Employment } \\
\hline Not employed & 60.50 & 38.68 & 46.79 & 13.18 & 19.04 & 31.07 \\
\hline Employed & 64.50 & 49.76 & 55.08 & 21.07 & 31.63 & 44.54 \\
\hline Total & 61.46 & 42.83 & 50.70 & 15.07 & 23.79 & 37.43 \\
\hline
\end{tabular}

aANC, adequate antenatal care; ANC4+, four antenatal care visits; ANC, antenatal care.

ANC outcomes were significantly associated with some controlling variables (residence, maternal education and employment).

Figure 1 presents the adjusted predicted probabilities of ANC outcomes derived from interaction terms between wealth and years of the survey from regressions shown in table 3. Overall, the figure suggests that the predicted probabilities of having ANC outcomes increases as the level of wealth index increases. Panel A suggests that with increasing the level of wealth index, the predicted probabilities of attending ANC4+ were lower in 2010 and 2016 compared with 2004. However, panel B shows that the predicted probabilities of accessing aANC were significantly higher in 2010 and 2010 compared with 2004.
The trend of inequalities in attending ANC4+ and accessing aANC

Panels A and B in figure 2 presents the CCs of attending ANC4+ and accessing aANC, respectively, over time (2004, 2010 and 2016). In both panels, the CCs were below the line of inequality, which means attending ANC4+ and accessing aANC were disproportionately concentrated among the rich women.

The extent and comparison of inequalities over time were estimated by using the Erreygers's indices with 95\% CIs as shown in panels $\mathrm{A}$ and $\mathrm{B}$ in figure 3 . The findings indicate that Cs for ANC4+ andaANC in all study years were positive and statistically significant in favour of rich women. This indicates that there was no improvement in the reduction of inequalities over 
Table 3 Multivariable logistic regression analysis: interaction models

\begin{tabular}{|c|c|c|c|c|}
\hline & \multicolumn{2}{|c|}{ At least four ANC visits } & \multicolumn{2}{|c|}{ Adequate ANC } \\
\hline & AOR & $(95 \% \mathrm{Cl})$ & AOR & $(95 \% \mathrm{Cl})$ \\
\hline Wealth & $1.17 \dagger$ & (1.08 to 1.28$)$ & $1.15 \dagger$ & (1.08 to 1.22$)$ \\
\hline \multicolumn{5}{|l|}{2004 (reference) } \\
\hline 2010 & $1.58^{\star}$ & (1.08 to 2.30$)$ & $0.46 \dagger$ & (0.35 to 0.59$)$ \\
\hline \multicolumn{5}{|l|}{ Year of survey $\ddagger$ wealth } \\
\hline \multicolumn{5}{|c|}{ 2004łwealth (reference) } \\
\hline $2010 \neq$ wealth & 1.03 & (0.93 to 1.14$)$ & 0.99 & (0.92 to 1.08$)$ \\
\hline 2016 ¥wealth & 1.09 & (0.99 to 1.20$)$ & 1.05 & (0.97 to 1.14$)$ \\
\hline $25-29$ & 1.05 & (0.87 to 1.27$)$ & 1.08 & (0.93 to 1.26$)$ \\
\hline $30-34$ & 1.05 & (0.86 to 1.28$)$ & 1.10 & (0.94 to 1.30$)$ \\
\hline $35-39$ & 1.03 & (0.84 to 1.26$)$ & 1.11 & (0.94 to 1.31$)$ \\
\hline $40-44$ & 1.06 & (0.84 to 1.34$)$ & 1.20 & (0.99 to 1.45$)$ \\
\hline $45-49$ & 0.97 & (0.70 to 1.35$)$ & 1.13 & (0.88 to 1.47$)$ \\
\hline \multicolumn{5}{|l|}{ Residence } \\
\hline \multicolumn{5}{|l|}{ Rural (reference) } \\
\hline Urban & $2.04 \dagger$ & (1.76 to 2.37$)$ & $1.27 \dagger$ & (1.11 to 1.46$)$ \\
\hline \multicolumn{5}{|l|}{ Maternal education } \\
\hline Living with a spouse & 0.94 & (0.84 to 1.05$)$ & 0.99 & (0.90 to 1.11$)$ \\
\hline \multicolumn{5}{|l|}{ Employment } \\
\hline \multicolumn{5}{|c|}{ Not employed (reference) } \\
\hline Employed & $1.25 \dagger$ & (1.14 to 1.38 ) & $1.09^{*}$ & (1.01 to 1.19 ) \\
\hline Constant & $0.06 \dagger$ & (0.04 to 0.08 ) & 0.79 & (0.62 to 1.01 ) \\
\hline
\end{tabular}

${ }^{*} \mathrm{P}<0.05$.

$\dagger \mathrm{P}<0.01$.

fInteraction.

ANC, antenatal care; AOR, adjusted OR.

the past 12 years, which reflects that the distribution remains highly prorich. We compared the inequality indices across the year of surveys, by using the F-statistic test. In all outcomes, the test showed the $\mathrm{p}<0.001$, and we rejected the null hypothesis that the indices are the same. Therefore, there was a significant increase in socioeconomic inequalities (prorich distribution) for these two ANC outcomes over time. The details for the trend and comparison of Cs are summarised in online supplemental table 1 .

\section{Decomposition of Cs}

Figure 4 presents the decomposition of Cs of ANC utilisation outcomes for each study year. In panel A, the results show that household wealth status was the largest contributor to inequality in ANC4+ in Tanzania. It contributed to socioeconomic inequalities for about $71 \%, 50 \%$ and $70 \%$ in 2004, 2010 and 2016, respectively, in favour of the advantaged. The second largest contributor was maternal education, which contributed about 23\%, 25\% and 15\% in 2004, 2010 and 2016, respectively, in favour 

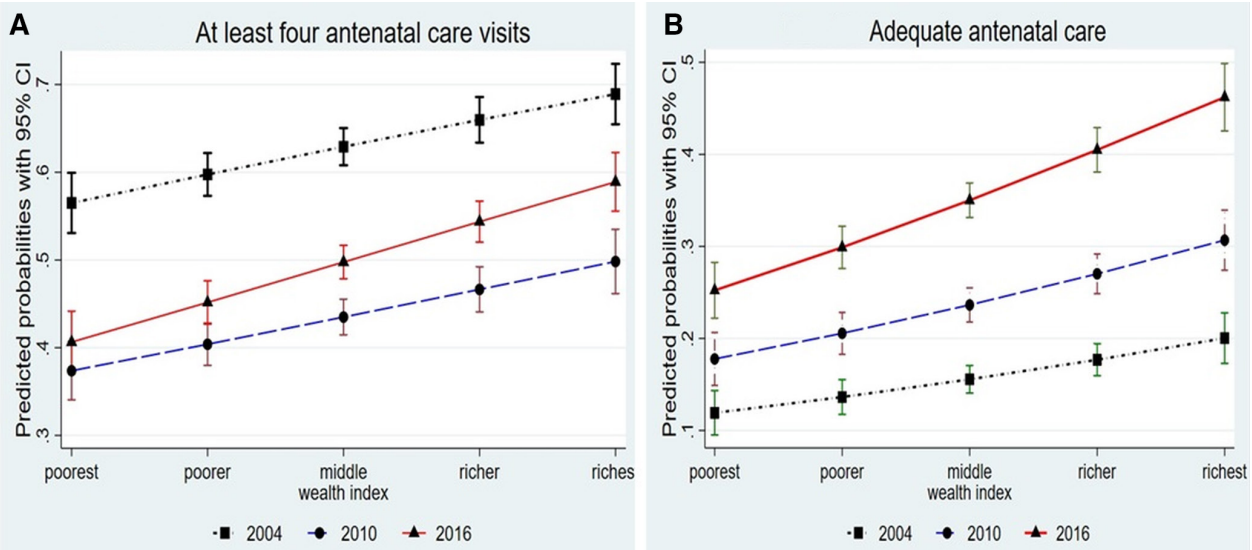

Figure 1 Adjusted predicted probabilities of antenatal care utilisation outcomes by year and the wealth index.

of the advantaged. The regional differences increased inequality by about $4 \%$ in 2016 compared with $1.5 \%$ in 2004. The details for the decomposition of $\mathrm{C}$ of attending ANC4+ are summarised in online supplemental table 2.

Similarly, for the attending ANC4+, the results (in panel B) show that household wealth status was the largest contributor to inequality in accessing aANC followed by the type of residence. Wealth status contributed about 50\%, 42\% and 51\% in 2004, 2010 and 2016, respectively, in favour of the advantaged, while the type of residence contributed about $28 \%, 37 \%$ and $26 \%$ in 2004, 2010 and 2016, respectively, in favour of those living in the urban areas. Another significant contributor was maternal education, which contributed to the inequality by about $16 \%, 11 \%$ and $13 \%$ in 2004, 2010 and 2016, respectively, in favour of women with primary, secondary and higher education levels. Regional effects contributed to inequality by about $3 \%$ in 2016 . The details for the decomposition of $\mathrm{C}$ of accessing aANC are summarised in online supplemental table 3 .

As the overall concentration indices for both outcome variable were positive in all study years, any independent variables with a significant positive contribution (such as fourth and highest categories of wealth status and secondary education level in online supplemental tables
2 and 3) would have reduced the prorich distribution of these outcome variables, if the concentration index of the contributing variables were zero (ie, were evenly distributed among the poor and the rich). The negative contributing variable (such as residence in online supplemental table 3) would otherwise have increased the prorich distribution for the outcome variable (aANC) if the concentration index of the contributing variable was zero. The percentage contribution of wealth index decreased in 2010 implies the reduction of prorich distribution for ANC utilisation.

\section{DISCUSSION}

The study highlights the significant persistence of socioeconomic inequalities in ANC utilisation (ANC4+ andaANC) among women of reproductive age in Tanzania from 2004 to 2016. The findings indicate that inequalities were prorich reflecting that women from wealthier households might have better access to ANC services due to fewer barriers compared with those in the poorest household quintile. ${ }^{2}$ Furthermore, there was an increase in inequalities of ANC utilisation (ANC4+ and $\mathrm{aANC}$ ) for the past 12 years. This observed persistent inequalities of ANC utilisation is contrary to the efforts
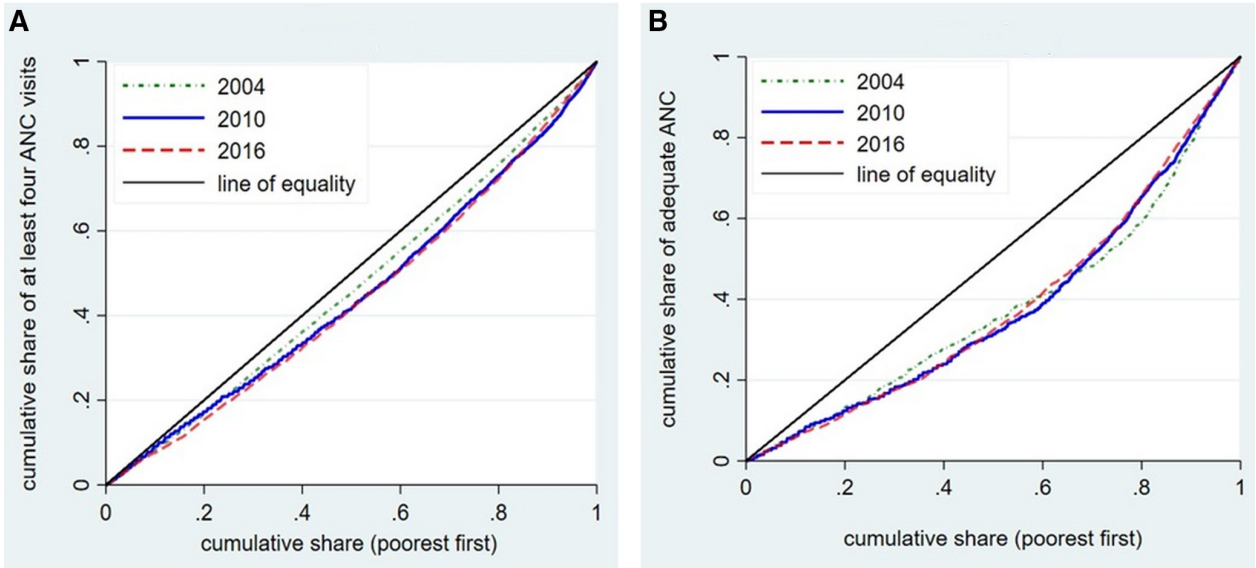

Figure 2 Concentration curves of antenatal care utilisation outcomes. ANC, antenatal care. 

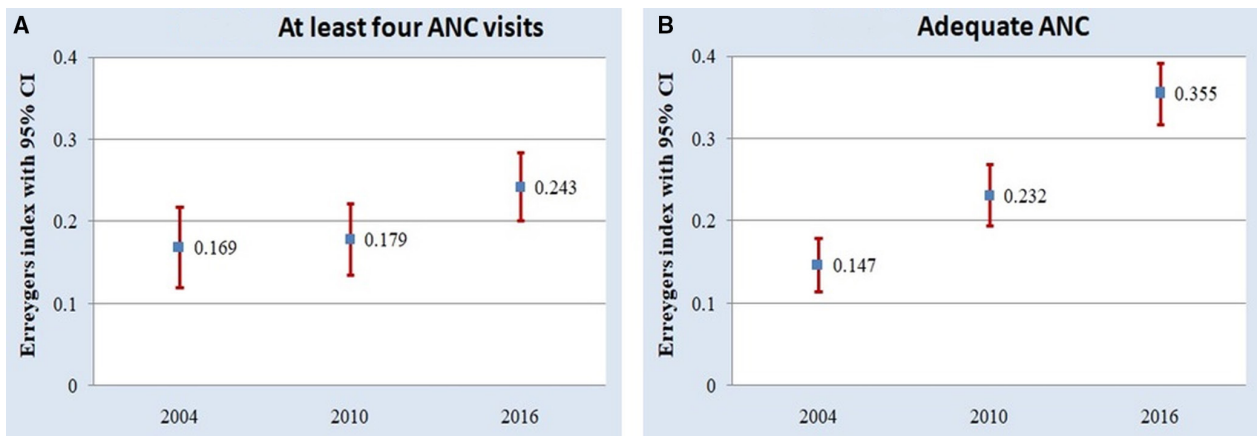

Figure 3 Inequality in antenatal care (ANC) utilisation outcomes over time.

made such as increased coverage rate of ANC services and the implementation of various maternal health policies in Tanzania. This suggests that the reduction of wealthrelated inequality is highly needed for the country to achieve universal maternal healthcare coverage. The reduction of wealth-related inequalities can be achieved through a call for an integrated policy approach interventions that include fiscal policies, government spending, social protection, labour market, employment policies and others.

The statistical evidence of positive Cs for attending ANC4+ and accessing aANC is consistent with findings of other studies conducted in Ghana, Ethiopia and Nigeria. ${ }^{38} 4041$ These persistent socioeconomic inequalities in ANC utilisation pose unanswered questions because ANC services that are free of charge make it cheap for every woman to use this care. However, this might be explained by other factors not related to socioeconomic differences such as facility or health providers' characteristics. Previous studies in Tanzania showed that if providers adhere to ANC standards, this increases the likelihood of pregnant women to receive adequate care, ${ }^{42}$ which prevents them from adverse pregnancy outcomes. ${ }^{43}$ Therefore, there is a need for improvements in both the socioeconomic profile of the population and the healthcare system to eliminate or reduce these socioeconomic inequalities in ANC utilisation in Tanzania.

Moreover, the study showed a persistent trend in socioeconomic inequalities in ANC utilisation over time. Despite the government efforts of significantly increasing the number of health facilities (at least each village has a dispensary that offers ANC services), socioeconomic inequalities in ANC utilisation remained unchanged over the past 12 years. Similar findings have been reported in previous studies conducted in Ethiopia. ${ }^{40}$ These persistent inequalities might be explained by the fact that the implemented ANC programmes in Tanzania have not sufficiently addressed the issue of equal opportunity to all as stipulated under SDGs. For example, one previous study reported disproportional distribution of equipment or medicines for maternal health services according to facility type and location. ${ }^{44}$ This may result in unnecessary out of stock of important ANC equipment and medicines resulting in unofficial fees such as laboratory and medication costs, which could be affordable to rich than poor women.

Additionally, despite the proportion of accessing aANC increased over time in all wealth quintiles, the proportion of attending ANC4+ decreased at the same time particularly among the poorest women. The observed finding might be explained by the fact that the government made much effort to improve maternal health services over time. ${ }^{26}{ }^{27}$ Therefore, the chance of accessing adequate care increased for those who managed to attend the ANC including the poorest women. However, a decrease in attending ANC4+ over time might be due to individual barriers such as getting permission, ${ }^{45}$ getting money to pay for advice or treatment, ${ }^{46}$ distance to the facility ${ }^{47}$ and lack of someone to escort. ${ }^{2}$ These barriers are more likely to be concentrated among the poorest than the richest women.

The decomposition analysis indicated that household wealth status and maternal education were the most contributors to the socioeconomic inequalities in ANC
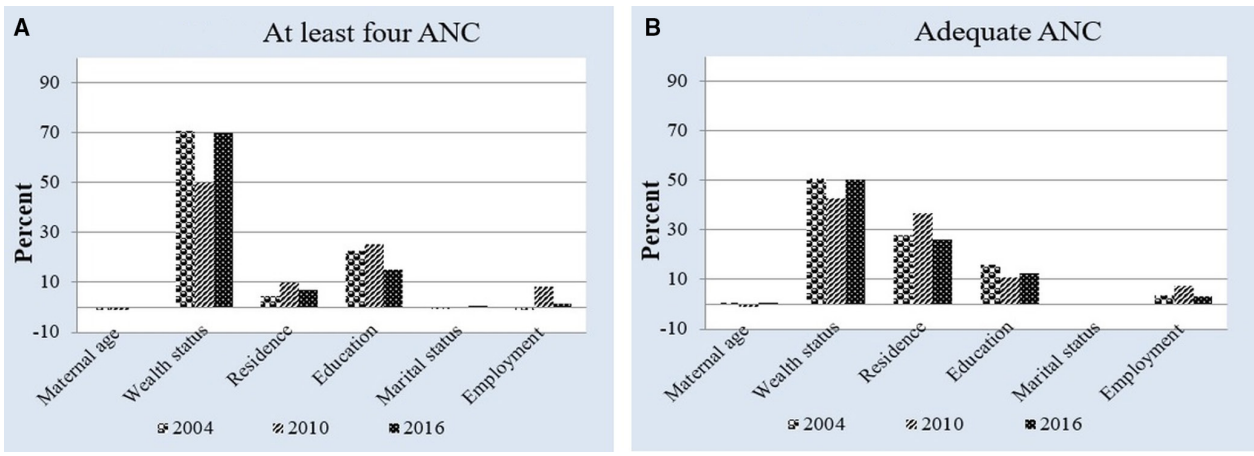

Figure 4 Relative contributions of factors to inequality in antenatal care (ANC) utilisation outcomes. 
utilisation in favour of rich women. This means these factors are preventing poor women from attending ANC4+ and accessing aANC. Of these three factors, wealth inequality was the major contributor to the socioeconomic inequalities in both attending ANC4+ and accessing aANC. Therefore, eliminating this reported wealth inequality might have reduced the socioeconomic inequalities (by increasing the proportion of poorer pregnant women) in attending ANC4+ and accessing aANC by $70 \%$ and $51 \%$, respectively, among poor women observed in 2016. Hence, achieving reductions in wealth inequality would be the first step in reducing socioeconomic inequalities in attending ANC4+ and accessing aANC. This finding is consistent with previous studies conducted in Namibia and Nigeria. ${ }^{41} 48$

Furthermore, the decomposition analysis highlighted the significant emphasis on the contribution of maternal education in addressing socioeconomic inequalities in ANC utilisation. Therefore, eliminating inequality in women's education might have reduced the socioeconomic inequalities (by increasing the proportion of poorer pregnant women) in attending ANC4+ and accessing aANC by $15 \%$ and $13 \%$, respectively, among poor women in 2016. Similar findings have been reported in other previous studies conducted in SSA. ${ }^{41}$ This finding might be explained by the fact that health-seeking behaviour among women has been associated with the level of education, which has been indicated as the major determinant of maternal health services utilisation in most previous studies. ${ }^{16}{ }^{49-51}$ Also, it has been shown that most households with low socioeconomic status in Tanzania and other SSA countries also have lower educational attainment. ${ }^{38}$ Therefore, achieving equalities in ANC utilisation should also target education policies by considering profound improvements for women from poor households.

The strength of this study is the use of three rounds of nationally representative samples (obtained by DHS) with high response rates that provide greater statistical power and generalisability to settings with a similar context. The use of the decomposition analysis approach helps to identify the most contributors to the socioeconomic inequalities in ANC utilisation that need specific policy interventions. Nevertheless, the study had some limitations, as the cross-sectional surveys meant that causality assumptions could not be inferred. Consequently, the results should be interpreted with caution. Also, there is a risk of recall bias that may have been introduced as a result of included women who had a live birth in the 5 years preceding the surveys. This might lead to either an overestimation or underestimation of the association between outcome and independent variables.

In summary, the current study provided evidence of 12-year persistent inequalities in ANC utilisation among women in Tanzania. Furthermore, it suggests that inequalities in ANC utilisation in all study years were largely due to inequalities in household wealth status and maternal education in favour of rich women. Therefore, the efforts of achieving universal health coverage in Tanzania should focus on reducing wealth inequality and target policies aimed at improving women's education from poor households.

Acknowledgements We would like to acknowledge the DHS programme for permitting us to access the Tanzania DHS 2004-2016 datasets.

Contributors DB originated the design of the study, performed statistical analysis and interpretation of data; DB and NB drafted, critically revised and approved the final manuscript for submission.

Funding The authors have not declared a specific grant for this research from any funding agency in the public, commercial or not-for-profit sectors.

Competing interests None declared.

Patient consent for publication Not required.

Provenance and peer review Not commissioned; externally peer reviewed.

Data availability statement Data are available in a public, open access repository. The datasets generated during the current study are available from within the Demographic and Health Survey Program repository: http://dhsprogram.com/data/ available-datasets.cfm.

Supplemental material This content has been supplied by the author(s). It has not been vetted by BMJ Publishing Group Limited (BMJ) and may not have been peer-reviewed. Any opinions or recommendations discussed are solely those of the author(s) and are not endorsed by BMJ. BMJ disclaims all liability and responsibility arising from any reliance placed on the content. Where the content includes any translated material, BMJ does not warrant the accuracy and reliability of the translations (including but not limited to local regulations, clinical guidelines, terminology, drug names and drug dosages), and is not responsible for any error and/or omissions arising from translation and adaptation or otherwise.

Open access This is an open access article distributed in accordance with the Creative Commons Attribution Non Commercial (CC BY-NC 4.0) license, which permits others to distribute, remix, adapt, build upon this work non-commercially, and license their derivative works on different terms, provided the original work is properly cited, appropriate credit is given, any changes made indicated, and the use is non-commercial. See: http://creativecommons.org/licenses/by-nc/4.0/.

ORCID iD

Deogratius Bintabara http://orcid.org/0000-0001-7877-870X

\section{REFERENCES}

1 Victora CG, Barros AJD, Axelson $\mathrm{H}$, et al. How changes in coverage affect equity in maternal and child health interventions in 35 countdown to 2015 countries: an analysis of national surveys. Lancet 2012;380:1149-56.

2 Bintabara D, Nakamura K, Seino K. Improving access to healthcare for women in Tanzania by addressing socioeconomic determinants and health insurance: a population-based cross-sectional survey. BMJ Open 2018;8:e023013.

3 Say L, Raine R. A systematic review of inequalities in the use of maternal health care in developing countries: examining the scale of the problem and the importance of context. Bull World Health Organ 2007;85:812-9.

4 Alam N, Hajizadeh M, Dumont A, et al. Inequalities in maternal health care utilization in sub-Saharan African countries: a multiyear and multi-country analysis. PLoS One 2015;10:e0120922.

5 Zere E, Kirigia JM, Duale S, et al. Inequities in maternal and child health outcomes and interventions in Ghana. BMC Public Health 2012;12:252.

6 Villar J, Ba'aqeel H, Piaggio G, et al. Who antenatal care randomised trial for the evaluation of a new model of routine antenatal care. Lancet 2001;357:1551-64.

7 World Health Organization (WHO). Who recommendation on antenatal care for positive pregnancy experience, 2016. Available: https://www.who.int/reproductivehealth/publications/maternal_ perinatal_health/anc-positive-pregnancy-experience/en/ [Accessed 23 Jul 2020].

8 Gupta S, Yamada G, Mpembeni R, et al. Factors associated with four or more antenatal care visits and its decline among pregnant women in Tanzania between 1999 and 2010. PLoS One 2014;9:e101893. 
9 Agho KE, Ezeh OK, Ogbo FA, et al. Factors associated with inadequate receipt of components and use of antenatal care services in Nigeria: a population-based study. Int Health 2018;10:172-81.

10 Heredia-Pi I, Servan-Mori E, Darney BG, et al. Measuring the adequacy of antenatal health care: a national cross-sectional study in Mexico. Bull World Health Organ 2016;94:452-61.

11 Raatikainen K, Heiskanen N, Heinonen S. Under-attending free antenatal care is associated with adverse pregnancy outcomes. BMC Public Health 2007;7:268.

12 Okedo-Alex IN, Akamike IC, Ezeanosike OB, et al. Determinants of antenatal care utilisation in sub-Saharan Africa: a systematic review. BMJ Open 2019;9:e031890.

13 Ministry of Health, Community Development, Gender, Elderly and Children (MoHCDGEC) [Tanzania Mainland], Ministry of Health $(\mathrm{MoH})$ [Zanzibar], National Bureau of Statistics (NBS), Office of the Chief Government Statistician (OCGS), ICF. Tanzania demographic and health survey and Malarialndicator survey (TDHS-MIS) 201516, Dar ES Salaam, Tanzania, and Rockville, Maryland, USA: MoHCDGEC, MoH, Nbs, OCGS, and ICF, 2016. Available: https:// dhsprogram.com/pubs/pdf/FR321/FR321.pdf [Accessed 23 Jul 2020].

14 Sakeah E, Okawa S, Rexford Oduro A, et al. Determinants of attending antenatal care at least four times in rural Ghana: analysis of a cross-sectional survey. Glob Health Action 2017;10:1291879.

15 Tekelab T, Chojenta C, Smith R, et al. Factors affecting utilization of antenatal care in Ethiopia: a systematic review and meta-analysis. PLoS One 2019;14:e0214848.

16 Orwa J, Mantel M, Mugerwa M, et al. Maternal healthcare services use in Mwanza region, Tanzania: a cross-sectional baseline survey. BMC Pregnancy Childbirth 2019;19:474.

17 Adewuyi EO, Auta A, Khanal V, et al. Prevalence and factors associated with underutilization of antenatal care services in Nigeria: a comparative study of rural and urban residences based on the 2013 Nigeria demographic and health survey. PLoS One 2018;13:e0197324.

18 Simkhada B, Teijlingen ERvan, Porter M, et al. Factors affecting the utilization of antenatal care in developing countries: systematic review of the literature. J Adv Nurs 2008;61:244-60.

19 Mehata S, Paudel YR, Dariang M, et al. Trends and inequalities in use of maternal health care services in Nepal: strategy in the search for improvements. Biomed Res Int 2017;2017:1-11.

20 Hajizadeh M, Alam N, Nandi A. Social inequalities in the utilization of maternal care in Bangladesh: have they widened or narrowed in recent years? Int J Equity Health 2014;13:120.

21 Molina HF, Nakamura K, Kizuki M, et al. Reduction in inequality in antenatal-care use and persistence of inequality in skilled birth attendance in the Philippines from 1993 to 2008. BMJ Open 2013;3:e002507.

22 Paredes KPP. Inequality in the use of maternal and child health services in the Philippines: do pro-poor health policies result in more equitable use of services? Int J Equity Health 2016;15:181.

23 Pulok MH, Sabah MN-U, Uddin J, et al. Progress in the utilization of antenatal and delivery care services in Bangladesh: where does the equity gap lie? BMC Pregnancy Childbirth 2016;16:200.

24 Pulok MH, Uddin J, Enemark U, et al. Socioeconomic inequality in maternal healthcare: an analysis of regional variation in Bangladesh. Health Place 2018;52:205-14.

25 Lee H-Y, Oh J, Kim R, et al. Long-term trend in socioeconomic inequalities and geographic variation in the utilization of antenatal care service in India between 1998 and 2015. Health Serv Res 2020:55:419-31.

26 Ministry of Health and Social Welfare (MoHSW). The National road map strategic plan to accelerate reduction of maternal, newborn and child deaths in Tanzania (2008-15), 2008. Available: http://www. mcdgc.go.tz/data/One_MNCH_plan.pdf [Accessed 23 Jul 2020].

27 Ministry of Health Community Development Gender Elderly and Children (MOHCDGEC). The national road map strategic plan to improve reproductive, maternal, newborn, child and adolescent health in Tanzania (2016 - 2020) (one plan II), 2016. Available: http:// globalfinancingfacility.org/sites/gff_new/files/documents/Tanzania One_Plan_II.pdf [Accessed 23 Jul 2020].

28 National Bureau of Statistics (NBS). Tanzania mainland and office of chief government statistician (OCGS) Zanzibar. 2012 Tanzania population and housing census, 2013. Available: http://www.tzdpg. or.tz/fileadmin/documents/dpg_internal/dpg_working_groups_
clusters/cluster_2/water/WSDP/Background_information/2012 Census_General_Report.pdf [Accessed 23 Jul 2020].

29 Muchie KF. Quality of antenatal care services and completion of four or more antenatal care visits in Ethiopia: a finding based on a demographic and health survey. BMC Pregnancy Childbirth 2017; $17: 300$.

30 Chama-Chiliba CM, Koch SF. Utilization of focused antenatal care in Zambia: examining individual- and community-level factors using a multilevel analysis. Health Policy Plan 2015;30:78-87.

31 Rwabilimbo AG, Ahmed KY, Page A, et al. Trends and factors associated with the utilisation of antenatal care services during the millennium development goals era in Tanzania. Trop Med Health 2020;48:38

32 Uddin J, Pulok MH, Johnson RB, et al. Association between child marriage and institutional delivery care services use in Bangladesh: intersections between education and place of residence. Public Health 2019;171:6-14.

33 O'Donnell O, van Doorslaer E, Wagstaff A. Analyzing health equity using household survey data: a guide to techniques and their implementation. The World Bank, 2007.

34 Kakwani N, Wagstaff A, van Doorslaer E. Socioeconomic inequalities in health: measurement, computation, and statistical inference. $J$ Econom 1997;77:87-103.

35 Erreygers G. Correcting the concentration index. $J$ Health Econ 2009;28:504-15.

36 Wagstaff $A$. The bounds of the concentration index when the variable of interest is binary, with an application to immunization inequality. Health Econ 2005;14:429-32.

37 Kjellsson G, Gerdtham U-G. On correcting the concentration index for binary variables. J Health Econ 2013;32:659-70.

38 Novignon J, Ofori B, Tabiri KG, et al. Socioeconomic inequalities in maternal health care utilization in Ghana. Int $J$ Equity Health 2019;18:141.

39 Wagstaff A, van Doorslaer E, Watanabe N. On decomposing the causes of health sector inequalities with an application to malnutrition inequalities in Vietnam. J Econom 2003;112:207-23.

40 Mezmur M, Navaneetham K, Letamo G, et al. Socioeconomic inequalities in the uptake of maternal healthcare services in Ethiopia. BMC Health Serv Res 2017;17:367.

41 Nwosu CO, Ataguba JE. Socioeconomic inequalities in maternal health service utilisation: a case of antenatal care in Nigeria using a decomposition approach. BMC Public Health 2019;19:1493.

42 Bintabara D, Nakamura K, Ntwenya J, et al. Adherence to standards of first-visit antenatal care among providers: a stratified analysis of Tanzanian facility-based survey for improving quality of antenatal care. PLoS One 2019;14:e0216520.

43 Amoakoh-Coleman M, Klipstein-Grobusch K, Agyepong IA, et al. Provider adherence to first antenatal care guidelines and risk of pregnancy complications in public sector facilities: a Ghanaian cohort study. BMC Pregnancy Childbirth 2016;16:369.

44 Bintabara D, Ernest A, Mpondo B. Health facility service availability and readiness to provide basic emergency obstetric and newborn care in a low-resource setting: evidence from a Tanzania national survey. BMJ Open 2019;9:e020608.

45 Wilunda C, Scanagatta C, Putoto G, et al. Barriers to utilisation of antenatal care services in South Sudan: a qualitative study in Rumbek North County. Reprod Health 2017;14:65.

46 Lowe M, Chen D-R, Huang S-L. Social and cultural factors affecting maternal health in rural Gambia: an exploratory qualitative study. PLoS One 2016;11:e0163653.

47 Mbiza CR, Kazembe A, Simwaka A. Barriers to health-seeking practices during pregnancy among adolescents in rural Blantyre, Malawi. Afr J Midwifery Womens Health 2014;8:59-65.

48 Zere $\mathrm{E}$, Tumusiime $\mathrm{P}$, Walker $\mathrm{O}$, et al. Inequities in utilization of maternal health interventions in Namibia: implications for progress towards mdg 5 targets. Int J Equity Health 2010;9:16.

49 Tsala Dimbuene Z, Amo-Adjei J, Amugsi D, et al. Women's education and utilization of maternal health services in Africa: a multi-country and socioeconomic status analysis. J Biosoc Sci 2018;50:725-48.

50 Rashid M, Antai D, Antai D. Socioeconomic position as a determinant of maternal healthcare utilization: a population-based study in Namibia. J Res Health Sci 2014;14:187-92.

51 Hahn RA, Truman BI. Education improves public health and promotes health equity. Int J Health Serv 2015;45:657-78.

52 Wenban-smith H. Rural-urban linkages : Tanzania case study, 2014. 